\title{
Efficacy of monepantel against lower developmental stages of a multi-resistant and susceptible Haemonchus contortus isolates: an in vitro study
}

\author{
L. LECOVÁ ${ }^{1 *}$, L. STUCHLÍKOVÁ ${ }^{1}$, J. LAMKA ${ }^{1}$, M. ŠPULÁK ${ }^{1}$, M. VÁRADY ${ }^{2}$, L. SKÁLOVÁ ${ }^{1}$ \\ ${ }^{1}$ Faculty of Pharmacy, Charles University in Prague, Heyrovského 1203, 500 05, Hradec Králové, Czech Republic, \\ E-mail: lecoval@faf.cuni.cz; ${ }^{2}$ Institute of Parasitology, the Slovak Academy of Sciences, Hlinkova 3, \\ 04001 Košice, Slovak Republic
}

\begin{abstract}
Summary
Monepantel (MOP) belongs to a new class of anthelmintic compounds, the amino-acetonitrile derivates, which have a different mode of action as the currently used anthelmintics. Many present studies confirmed the high efficacy of MOP against fourth larval and adult stages of Haemonchus contortus. The objective of this study was to determine in vitro efficacy of MOP against lower development stages (eggs, $\mathrm{L}_{1}-\mathrm{L}_{3}$ larvae) and to compare it between resistant and susceptible isolates of $H$. contortus. For this purpose, two in vitro tests - egg hatch test and micro-agar larval development test were used. Results were quantified as $50 \%$ lethal concentration $\left(\mathrm{LC}_{50}\right), 99 \%$ lethal concentration $\left(\mathrm{LC}_{99}\right)$ and resistance factor (RF). This study revealed the high efficacy against lower larval stages $\left(\mathrm{L}_{1}-\mathrm{L}_{3}\right)$ of both resistant and susceptible strains of this parasite. Larval susceptibility was not dependent of the sensitivity status of the nematode isolate. On the other hand, ovicidal effect of MOP was very low.
\end{abstract}

Keywords: amino-acetonitrile derivatives; antihelmintic resistance; micro-agar larval development test; monepantel; nematode

\section{Introduction}

The resistance of nematodes to anthelmintic drugs becomes a serious problem and there are many reports of resistance from several parts of the world for every year. Resistance has now been reported to all of the broad spectrum anthelmintic classes currently available, namely to the benzimidazoles (e.g., flubendazol, albendazol, and fenbendazol), imidazothiazoles (e.g., levamisole), and to macrocyclic lactones (e.g., ivermectin) (Leathwick, 2012). Amino-acetonitrile derivates (AADs) is a new class of anthelmintic compounds discovered in 2008. The AADs candidates seem to have a novel mode of action involving a unique, nematode-specific clade of acetylcholine receptor subunits. These drugs cause hypercontraction of the body wall muscles leading to paralysis, spasmodic contractions of the anterior portion of the pharynx and ultimately death of adult nematodes (Kaminsky et al., 2008) So far, MOP (Fig. 1) is the only representative of AADs approved and marketed under the trade name Zolvix ${ }^{\circledR}$ (Novartis Animal Health Inc., Switzerland). This oral solution is a broad spectrum anthelmintic for the treatment and control of gastro-intestinal nematode infections and associated diseases in sheep including lambs, hoggets, breeding rams and ewes. Spectrum of activity includes main species of gastro-intestinal parasites. Many authors reported the efficacy of MOP against adult $H$. contortus and also against the fourth larval stage (e.g. Baker et al., 2012, Hosking et al., 2009, Sager et al., 2012, Stein et al., 2012). However, the information about its effect against the lower larval stages or eggs of $H$. contortus has not been available yet. Addressing this fact, the present in vitro study was designed to test the in vitro anthelmintic effects of MOP on two isolates of $H$. contortus, using an egg hatch test (EHT) and micro-agar larval development test (MALDT) (Várady et al., 2009). Thiabendazole (TBZ) as a reference anthelmintic drug with ovicidal and larvicidal efficacy was included in this study.

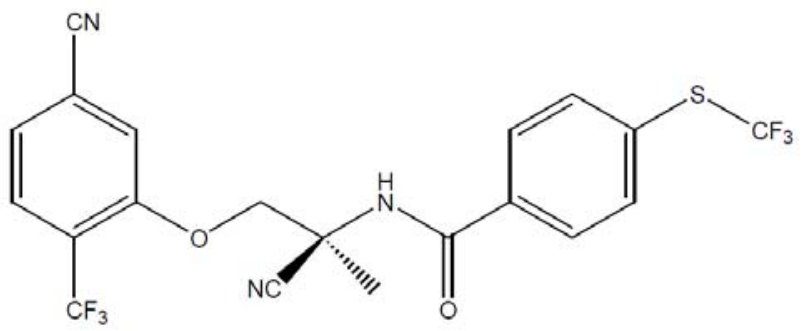

Fig. 1. Chemical structure of MOP: N-[(1S)-1-cyano-2-(5-cyano-2trifluoromethyl- phenoxy)-1-methylethyl]- 4trifluoromethylsulfanylbenzamide 


\section{Materials and methods}

\section{Chemicals}

MOP was prepared at the Department of Organic Chemistry (Faculty of Pharmacy in Hradec Králové, Charles University in Prague, Czech Republic) according to Kaminsky et al. (2008) with minor modifications (Stuchlíková et al., 2013). The structure and purity of prepared substance was tested using nuclear magnetic resonance and liquid chromatography with mass spectrometry. All other chemicals were obtained from Sigma-Aldrich (Prague, Czech Republic).

\section{Parasite material}

One susceptible isolate of $H$. contortus - ISE and one resistant strain - White river (WR) have been used in this study. The $H$. contortus ISE strain is an anthelminthicsusceptible inbred type of the SE strain (Roos et al., 2004), which had been isolated from the field before benzimidazole anthelmintics were introduced to the market. The South African, multi-resistant WR isolate has been isolated from the field, and it has demonstrated resistance to ivermectin $(30 \%$ efficacy at $0.2 \mathrm{mg} / \mathrm{kg})$ as well as the benzimidazoles, rafoxanide and closantel (Van Wyk \& Malan, 1988).

Four pairs of parasite-free Suffolk lambs (5 - 6 months old) from Běleč (Czech Republic) were orally infected with $\mathrm{L}_{3}$ larvae of $H$. contortus. Each animal obtained a suspension with $5000-6000 \mathrm{~L}_{3}$ larvae. In each pair, one lamb was infected by ISE and second one by WR strain. $H$. contortus eggs obtained from individual sheep were investigated independently for comparison of results. Faecal samples were collected on day 35 after inoculation, and nematode eggs for egg hatch tests and micro-agar larval development tests were collected by differential sieving through three stacked sieves of 250-, 100-, and $25-\mu \mathrm{m}$ mesh, successively. The material retained on the $25-\mu \mathrm{m}$ mesh sieve was washed with water, sedimented, and floated (Coles et al., 1992), followed by washing over a $20-\mu \mathrm{m}$ mesh sieve with water. Flotation was performed by less aggressive modified Sheather's solution instead of saturated sodium chloride. The eggs obtained were subsequently used for in vitro tests.

\section{In vitro egg hatch test}

The test procedure followed that recommended by the World Association for the Advancement of Veterinary Parasitology (WAAVP) (Coles et al., 1992). There are several variations of the test but they are all based on the ovicidal properties of the anthelmintic drugs and the ability of eggs to develop and hatch in different concentrations of the anthelmintics (Hunt \& Taylor, 1989). Egg suspension $(1.99 \mathrm{ml})$ was placed in wells and then $10 \mu \mathrm{l}$ of MOP/TBZ solutions added. The final concentrations of $\mathrm{MOP} / \mathrm{TBZ}$ were $0.025,0.05,0.1,0.3,0.5,2.5$ and $5.0 \mu \mathrm{g} . \mathrm{ml}^{-1}$. 24-well microtitre plates were sealed to prevent drying out and incubated for $48 \mathrm{~h}$ at $27^{\circ} \mathrm{C}$ before being stopped by addition of $10 \mu \mathrm{l}$ of Lugol's solution to each well. Eggs and larvae were counted from each well. The test was performed in two replicates for each drug concentration with negative control sample (without drug) and independent experiments were repeated four-times.

\section{In vitro micro-agar larval development test}

MALDT was performed as described by Coles et al. (2006). The test was performed on 96 microtitre well plates. Stock solutions of MOP/TBZ were prepared by predissolving the drugs in dimethylsulfoxide (DMSO) with subsequent dilution in distilled water (1:4). The final concentrations of MOP/TBZ were $0.0006,0.00125,0.0025$, $0,005,0.01,0.02,0.04,0.08,0.16,0.32,0.64$, and $1.28 \mu \mathrm{g} \cdot \mathrm{ml}^{-1}$. To each well $10 \mu \mathrm{l}$ of drug solution was added (or DMSO, in the control wells) as well as $150 \mu \mathrm{l}$ of $2 \%$ agar at $45{ }^{\circ} \mathrm{C}$. After the gel had solidified, $10 \mu \mathrm{l}$ of culture medium $(1 \mathrm{~g}$ yeast extract plus $90 \mathrm{ml} 0.85 \% \mathrm{NaCl}$ autoclave for $20 \mathrm{~min}$; add $3 \mathrm{ml}$ of $10 \mathrm{x}$ concentrated Earle's solution per $27 \mathrm{ml}$ of yeast extract) and $10 \mu \mathrm{l}$ of a suspension diluted 1:1 with amphotericin B (SigmaAldrich, Czech Republic) containing 50 - 80 eggs were added on the top of agar matrix. To prevent evaporation, the outer most wells on each plate were filled with distilled water. The plates were then incubated for 7 days at $27^{\circ} \mathrm{C}$ and the test was finished by adding $10 \mu \mathrm{l}$ of Lugol's solution into each well. Before counting, the whole liquid content of each well was collected and transferred to new 96 microtitre well plates. The numbers of unhatched eggs and $\mathrm{L}_{1}-\mathrm{L}_{3}$ larvae in each well were counted under an inverted microscope. The test was performed in two replicates for each drug concentration and it was repeated in four independent experiments.

\section{Data analysis}

Results of the egg hatch test and larval development test are presented as $\mathrm{LC}_{50}$ and $\mathrm{LC}_{99}$ values, which are defined as the anthelmintic concentrations where the hatching and development of eggs to the $\mathrm{L}_{3}$ stage is inhibited by $50 \%$ and $99 \%$, respectively. The data were analysed using a logistic regression model to determine $\mathrm{LC}_{50}$ and $\mathrm{LC}_{99}$ (Dobson et al., 1987). The $\mathrm{LC}_{50}$ gives information on the resistance of the average worm in the population, and $\mathrm{LC}_{99}$ shows which proportion of the population is the most resistant. Significant differences $(P \leq 0.05)$ between $\mathrm{LC}_{50}$ or $\mathrm{LC}_{99}$ values obtained for MOP and for the differences between $\mathrm{LC}_{50}$ or $\mathrm{LC}_{99}$ values within each isolate, were identified by a one-way ANOVA analysis followed by a Bonferroni post hoc test (Instat, GraphPad Software, San Diego, USA). The degree of anthelmintic resistance was expressed as the resistance factor (RF), calculated as the $\mathrm{LC}_{50}$ or $\mathrm{LC}_{99}$ value for the resistant isolate (WR) divided by the respective value for the susceptible isolate (ISE). 


\section{Results and discussion}

The objective of this study was to determine the efficacy of MOP, against lower development stages (eggs, $\mathrm{L}_{1}-\mathrm{L}_{3}$ larvae) and to compare it between resistant and susceptible isolates of $H$. contortus. For this purpose, two in vitro tests - EHT and MALDT were used.

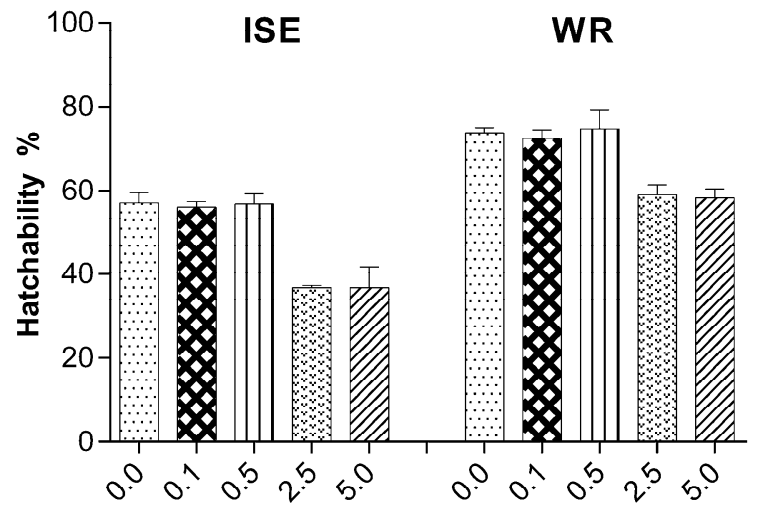

Monepantel $\mu g . \mathrm{ml}^{-1}$

Fig. 2. Hatchability of eggs in EHT with different concentrations of MOP

A modified protocol of the EHT for detection of MOP efficacy was used for Ancylostoma ceylanicum (Tritten et al., 2011) but its application for $H$. contortus has not been described till now. Results of EHT of MOP efficacy in $H$. contortus are presented in Fig. 2. At concentration range $0.025-0.5 \mu \mathrm{g} \cdot \mathrm{ml}^{-1}$, MOP did not affect hatching of eggs from both strains. Hatchability of eggs treated with these MOP concentrations that are achievable in the faeces of treated animals (Skripsky et al., 2010), was similar as in the negative control without drug. In eggs treated with high MOP concentrations ( 2.5 and $\left.5.0 \mu \mathrm{g} \cdot \mathrm{ml}^{-1}\right)$, hatchability was reduced approximately by $15 \%$ (WR strain) and by $20 \%$ (ISE strain). Even the highest concentration $5.0 \mu \mathrm{g} \cdot \mathrm{ml}^{-1}$ was not appropriate for accurately determining the $\mathrm{LC}_{50}$. As it was presented by Tritten et al. (2011) in Ancylostoma ceylanicum MOP showed a moderate inhibition of hatching (reduction by $31.4 \%$ at concentration of MOP $10 \mu \mathrm{g} \cdot \mathrm{ml}^{-1}$ ), which is approximately in agreement with our results obtained at twice lower concentration.

Compared to MOP, TBZ had significant ovicidal effect at a concentration as low as $0.025 \mu \mathrm{g} . \mathrm{ml}^{-1}$ in ISE and WR strains, respectively. $\mathrm{LC}_{50}$ of TBZ reached $0.0464 \mu \mathrm{g} \cdot \mathrm{ml}^{-1}$ in ISE and $0.1009 \mu \mathrm{g} . \mathrm{ml}^{-1}$ in WR strain. These results are in agreement with results of Várady et al. (2007) where $\mathrm{LD}_{50}$ of TBZ for susceptible strain was $0.0333 \mu \mathrm{g} \cdot \mathrm{ml}^{-1}$ and for resistant strain was $0.1080 \mu \mathrm{g} \cdot \mathrm{ml}^{-1}$.

With aim to study MOP efficacy on $\mathrm{L}_{1}-\mathrm{L}_{3}$ larvae of $H$. contortus, MALDT was used. Both in vitro techniques MALDT and LDT show comparable and reliable results (Várady et al., 2009). These tests have high sensitivity which allows reveal relatively small proportions of resistant worms in the population. Table 1 shows $\mathrm{LC}_{50}$ and $\mathrm{LC}_{99}$ values for MOP and TBZ inhibition of larval development in susceptible and resistant isolates obtained by MALDT. The MOP $\mathrm{LC}_{50}$ for resistant strain was $0.00344 \mu \mathrm{g} \cdot \mathrm{ml}^{-1}$ and the MOP LC 99 was $0.01107 \mu \mathrm{g} \cdot \mathrm{ml}^{-1}$. For susceptible strain, the values of $\mathrm{LC}_{50}$ and $\mathrm{LC}_{99}$ for MOP were $0.00337 \mu \mathrm{g} . \mathrm{ml}^{-1}$ and $0.00840 \mu \mathrm{g} \cdot \mathrm{ml}^{-1}$, respectively. The values of $\mathrm{TBZ}$ for WR strain were $0.01613 \mu \mathrm{g} \cdot \mathrm{ml}^{-1}$ for $\mathrm{LC}_{50}$ and $0.4210 \mu \mathrm{g} \cdot \mathrm{ml}^{-1}$ for $\mathrm{LC}_{99}$. For ISE strain $\mathrm{LC}_{50}$ was $0.00742 \mu \mathrm{g} . \mathrm{ml}^{-1}$ and $\mathrm{LC}_{99}$ was 0.1803 $\mu \mathrm{g} . \mathrm{ml}^{-1}$. A comparison of MOP $\mathrm{LC}_{50}$ or $\mathrm{LC}_{99}$ values in WR strain with MOP $\mathrm{LC}_{50}$ or $\mathrm{LC}_{99}$ values in ISE strain did not demonstrate significant differences $(\mathrm{P}<0.05)$ in $\mathrm{MOP}$ efficacy, unlike the values for TBZ. The values of resistance factor (RF) (see Table 2) express the differences of MOP and TBZ anthelmintic efficacies between WR and ISE strains. While TBZ had significantly decreased efficacy on development of $H$. contortus larvae of WR strain than ISE strain, MOP was similarly effective in both strains as low values of resistant factors $\left(\mathrm{RF}_{50}=1.02\right.$ and $\left.\mathrm{RF}_{99}=1.31\right)$ were obtained. Due to the widespread anthelmintic resistance this high sensitivity of $H$. contortus resistant strain is a big advantage for the successful therapy without a significant organism burden caused by high doses of drugs and their metabolites.

As shown earlier (Várady et al., 2007), calculation of $\mathrm{LC}_{99}$ values can significantly increase the sensitivity of the test and identify resistance even if only a small proportion of the worm population is resistant (high values of RF $>100$ are commonly obtained). The larval development tests are the only ones that allow the detection of resistance against all the drugs, irrespective of their mode of action. Several methods have been described, but reproducibility, linearity of the dose-response and susceptibility differ. In vitro anthelmintic inhibition of larval development of the freeliving stages in $H$. contortus was tested by more authors (Bartíková et al., 2010, Gill et al., 1995, Kotze et al., 2002, Le Jambre et al., 1995, Várady et al., 2007, Várady et al., 2009). Drugs such as benzimidazoles, imidazothiazoles and macrocyclic lactones show relatively good larvicidal activity in susceptible strains but they were mostly insufficient in resistant strains. Efficacy of MOP against lower development stages of resistant strains of $H$. contortus has advantage that may partially limit development to infective third larval stages and their survival on pasture and thus reduce the risk of infection.

Table 1. Lethal concentrations (LC; $\mu \mathrm{g} \cdot \mathrm{ml}^{-1}$; mean $\pm \mathrm{SD}$ ) of MOP/TBZ for resistant (WR) and susceptible (ISE) isolates of Haemonchus contortus obtained by in vitro micro-agar larval development tests

\begin{tabular}{|c|c|c|c|c|}
\hline \multirow{2}{*}{ Drug } & \multicolumn{2}{|c|}{ WR } & \multicolumn{2}{|c|}{ ISE } \\
\hline & $\mathrm{LC}_{50}$ & $\mathrm{LC}_{99}$ & $\mathrm{LC}_{50}$ & $\mathrm{LC}_{99}$ \\
\hline MOP & $0.00344 \pm 0.00088$ & $0.01107 \pm 0.00493$ & $0.00337 \pm 0.00493$ & $0.00840 \pm 0.00119$ \\
\hline TBZ & $0.01613 \pm 0.00329$ & $0.42910 \pm 0.15110$ & $0.00742 \pm 0.00139$ & $0.01803 \pm 0.00652$ \\
\hline
\end{tabular}


Table 2. Resistance factors (RF) of resistant (WR) and susceptible (ISE) isolates of Haemonchus contortus

(abbreviations and methods are the same as in Table 1)

\begin{tabular}{ccc}
\hline Drug & $\mathrm{RF}_{50}{ }^{\mathrm{a}}$ & $\mathrm{RF}_{99}{ }^{\mathrm{b}}$ \\
\hline MOP & 1.02 & 1.31 \\
$\mathrm{TBZ}$ & 2.17 & 23.80
\end{tabular}

${ }^{\mathrm{a}} \mathrm{LC}_{50}$ for WR divided by $\mathrm{LC}_{50}$ for ISE

${ }^{\mathrm{b}} \mathrm{LC}_{99}$ for WR divided by $\mathrm{LC}_{99}$ for ISE

In conclusion, our study showed that MOP has no significant ovicidal effect. Therefore it should be taken in account that dung with $H$. contortus eggs remains still infective after treatment of animals with MOP. On the other hand, MOP exhibited significant larvicidal effect. The in vitro larval susceptibility to MOP was similar in susceptible ISE strain and multi-resistant WR strain.

\section{Acknowledgements}

This project was supported by the operational programme ECOP, registration number CZ.1.07/2.3.00/30.0061, Increasing of the R\&D capacity at Charles University through new positions for graduates of doctoral studies, Czech Republic, by Czech Science Foundation, grant No. P502/10/0217, by Grant Agency of Charles University, grant No. 673612/B-CH/2012, by the Charles University in Prague (research projects SVV 267 004), and by Slovak Research and Development Agency Project No. APVV0539-10.

\section{References}

Baker, K. E., George, S. D., Stein, P. A., Seewald, W., Rolfe, P. F., Hosking, B. C. (2012): Efficacy of monepantel and anthelmintic combinations against multiple-resistant Haemonchus contortus in sheep, including characterisation of the nematode isolate. Vet. Parasitol., 186 (3 4), (25): 513 - 517. DOI: 10.1016/j.vetpar.2011.11.060

BARTíKovÁ, H., SKÁlovÁ, L., LAMKA, J., SZOTÁKOVÁ, B., VÁRADY, M. (2010): The effects of flubendazole and its metabolites on the larval development of Haemonchus contortus (Nematoda: Trichostrongylidae): an in vitro study. Helminthologia, 47 (4): 269 - 272. DOI: 10.2478/s11687-010-0042-7

Coles, G. C., Bauer, C., Borgsteede, F. H. M., Geerts, S., Klei, T. R., TAYlor, M. A., WAller, P. J. (1992): World Association for the Advancement of Veterinary Parasitology (WAAVP) Methods for the detection of anthelmintic resistance in nematodes of veterinary importance. Vet. Parasitol., $44(1-2)$ : 35 - 44. DOI: 10.1016/0304-4017(92)90141-U

Coles, G. C., Jackson, F., Pomroy, W. E., Prichard, R. K., Von SAmson-Himmelstjerna, G., Silvestre, A., TAYLOR, M. A., VERCRUYSSE, J. (2006): The detection of anthelmintic resistance in nematodes of veterinary importance. Vet. Parasitol., 136 (3 - 4): 167 - 185. DOI: 10.1016/j.vetppar.2005.11.019
Dobson, R. J., GRIFfiths, D. A., Donald, A. D., WALler, P. J. (1987): A genetic model describing the evolution of levamisole resistance in Trichostrongylus colubriformis, a nematode parasite of sheep. IMA J. Math. Appl. Med. Biol., 4: 279 - 293. DOI: 10.1093/imammb/4.4.279

Gill, H. J., Redwin, M. J., VAn WyK, A. J., Lacey, E. (1995): Avermectin inhibition of larval development in Haemonchus contortus - Effects of ivermectin resistance. Int. J. Parasitol., 25 (4): $463-470$

Hosking, B. C., Dobson, D. P., Stein, P. A., Kaminsky, R., Bapst, B., Mosimann, D., Mason, P. C., Seewald, W., Strehlau, G., SAGER, H. (2009): Dose confirmation studies for monepantel, an amino-acetonitrile derivative, against fourth stage gastro-intestinal nematode larvae infecting sheep, Vet. Parasitol., 160 (3 - 4) (23): 251-257. DOI: 10.1016/j.vetpar.2008.11.028

HunT, K. R., TAYLOR, M. A. (1989): Use of the egg hatch assay on sheep faecal samples for the detection of benzimidazole resistant worms. Vet. Rec., 125: 153 - 154 . DOI: $10.1136 / v r .125 .7 .153$

Kaminsky, R., Ducray, P., Jung, M., Clover, R., RufeNER, L., BOUVIER, J., WeBER, S., Wenger, A., WielandBerghausen, S., Goebel, T., Gauvry, N., Pautrat, F., Skripsky, T., Froelich, O., Komoin-OKa, C., WestLund, B., SLuder, A., MÄSER, P. (2008): A new class of anthelmintics effective against drug-resistant nematodes. Nature, 452 (7184): 176 - 180. DOI: 10.1038/nature06722 Kotze, A. C., Dobson, R. J., Tyrrell, K. L., Stein, P. A. (2002): High-level ivermectin resistance in a field isolate of Haemonchus contortus associated with a low level of resistance in the larval stage: implications for resistance detection. Vet.. Parasitol., 108 (3): 255 - 263. DOI: 10.1016/0020-7519(94)00087-5

LEATHWICK, D. M. (2012): Modelling the benefits a new class of anthelmintic in combination. Vet. Parasitol., 186: 93 - 100. DOI: 10.1016/j.vetpar.2011.11.050

Le Jambre, L. F., Gill, J. H., Lenane, I. J., Lacey, E. (1995): Characterisation of an avermectin resistant strain of Australian Haemonchus contortus. Int. J. Parasitol., 25 (6): 691 - 698. DOI: 10.1016/0020-7519(94)00200-8

Roos, M. H., Otsen, M., Hoekstra, R., Veenstra, J. G., LENSTRA, J. A. (2004): Genetic analysis of inbreeding of two strains of the parasitic nematode Haemonchus contortus. Int. J. Parasitol., 34: 109 - 115. DOI: 10.1016/j.ijpara. 2003.10.002

SAger, H., Bapst, B., Strehlau, G. A., Kaminsky, R. (2012): Efficacy of monepantel, derqantel and abamectin against adult stages of a multi-resitant Haemonchus contortus isolate. Parasitol. Res., 111: 2205 - 2207. DOI: 10.1007/s00436-012-2949-Z

SKRIPSKY, T., HOFFMAN, S. (2010): Assessment of risk of monepantel faecal residues to dung fauna. Aust. Vet. J., 88 (12): 490 - 496. DOI: 10.1111/j.1751-0813.2010.00645.x Stein, P. A., George, S. D., Rolfe, P. F., Hosking, B. C. (2012): Safety and efficacy against fourth-stage gastrointestinal nematode larvae, of monepantel in 6-week old lambs. Vet. Parasitol., 185: 339 - 342. DOI: 10.1016/j.vetpar.2011.10.020 
StuchlíkovÁ, L., JiRÁsko, R., LAMKA, J., SzotÁKovÁ, B., VOKŘÁL, I., ŠPULÁK, M., HOLČAPEK, M., BARTÍKOVÁ, H., POUR, M., SKÁlOVÁ, L. (2013): Investigation of the metabolism of monepantel in ovine hepatocytes by UHPLC/MS/MS. Anal. Bioanal. Chem., 405: 1705 - 1712. DOI: $10.1007 / \mathrm{s} 00216-012-6584-4$

Tritten, L., Silbereisen, A., KeISE, J. (2011): In Vitro and In Vivo efficacy of monepantel (AAD 1566) against laboratory models of human intestinal nematode infections. PLoS Negl. Trop. Dis., 5 (12): 1457

VAN WYK, J. A., Malan, F. S. (1988): Resistance of field strains of Haemonchus contortus to ivermectin, closantel, rafoxanide and the benzimidazoles in South Africa. Vet. Rec., 123: 226 - 228. DOI: 10.1136/vr.123.9.226

VÁRADY, M., ČUdEKOVÁ, P., ČORBA, J. (2007): In vitro detection of benzimidazole resistance in Haemonchus contortus: Egg hatch test versus larval development test. Vet. Parasitol., 149: $104 \quad-110 . \quad$ DOI: 10.1016/j.vetpar.2007.07.011

VÁRAdy, M., ČORBA, J., LETKOVÁ, V., KovÁČ, G. (2009): Comparison of two version of larval development test to detect anthelmintic resistance in Haemonchus contortus. Vet. Parasitol., 160: 267 - 271. DOI: 10.1016/j.vetpar.20 08.11 .010 